\title{
Biogeografia do Rio Grande do Sul
}

\author{
Bruno Ribeiro de Oliveira $^{(a)}$, Márcia da Silva Jorge ${ }^{(b)}$, Andrei Carlesso ${ }^{(c)}$, Mateus Pessetti $^{(\mathrm{d})}$
}

(a) Acadêmico do Curso de Geografia, Instituto de Ciências Exatas e Geociências, Universidade de Passo Fundo (UPF). E-mail: brunoo.geo@hotmail.com

(b) Professora do Curso de Geografia, Instituto de Ciências Exatas e Geociências, Universidade de Passo Fundo (UPF). E-mail: msjgeo@gmail.com

(c) Acadêmico do Curso de Geografia, Instituto de Ciências Exatas e Geociências, Universidade de Passo Fundo (UPF). E-mail: andrei.carlesso@ hotmail.com

(d) Acadêmico do Curso de Geografia, Instituto de Ciências Exatas e Geociências, Universidade de Passo Fundo

(UPF). E-mail: (mateuspessetti@hotmail.com)

\section{EIXO: BIOGEOGRAFIA, MANEJO DE ÁREAS NATURAIS E PROTEGIDAS: CONSERVAÇÃO DA BIODIVERSIDADE}

\section{Resumo:}

O presente trabalho tem, como cerne, a caracterização dos biomas presentes no Estado do Rio Grande do Sul, contemplando sua fauna e flora e a problematização quanto às influências humanas sobre eles. Essas, causadas por inúmeras ações em decorrência de pressões econômicas, políticas e sociais, que afetam significativamente os ecossistemas. Serão abordadas diversas questões, como: as diferenças entre os dois biomas (Mata Atlântica e Pampa) e suas particularidades bióticas e geográficas, juntamente com outras influências a nível social. Destaca-se também, a importância da preservação dos ecossistemas, visando à preocupação com as ameaças à biodiversidade do Estado, em especial da Estação Ecológica do Taim, que constitui um dos principais ecossistemas gaúchos, contemplando riquezas únicas e particulares do Bioma Pampa.

Palavras chave: Biogeografia; Biomas; Ecossistemas; Rio Grande do Sul.

\section{Introdução}

A Biogeografia representa a união entre a Geografia física e a Geografia Humana na Biosfera, pois a vegetação de qualquer parte da Terra é o reflexo do clima e da ecologia locais, tornando o estudo dos aspectos biogeográficos relevantes pela complexidade de sua área de abrangência. Além disso, oferece amplas possibilidades de integrar diversas áreas do conhecimento para aplicações práticas no setor de conservacionismo e aproveitamento racional dos recursos naturais.

Nesse contexto, o estado do Rio Grande do Sul possui uma grande diversidade de fauna e flora, distribuídos em dois importantes biomas brasileiros: a Mata Atlântica e o Pampa (Figura 1). Nessa perspectiva, o presente trabalho visa caracterizar os aspectos biogeográficos do Estado do Rio Grande do Sul, considerando a importância da biodiversidade para o equilíbrio dos ecossistemas formadores desses 


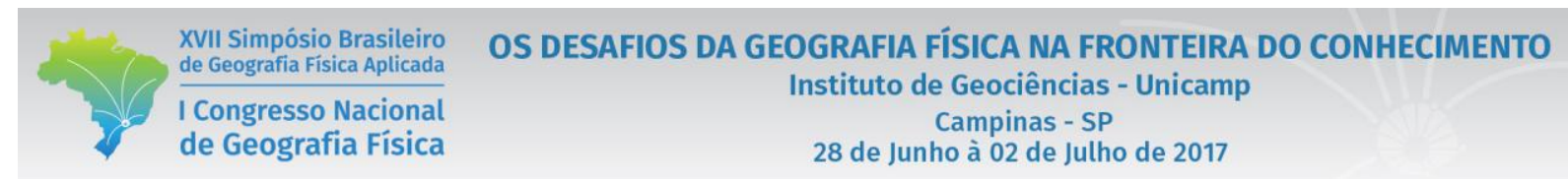

biomas, os quais apresentam uma complexa relação entre fatores bióticos e abióticos, e a intervenção humana, acenando para uma permanente transformação da paisagem.

Dessa forma, destacam-se os processos que promovem modificações na paisagem ao longo do tempo, através de fatores geológicos, geomorfológicos, climáticos e antrópicos que acentuam significativas diferenças entre os dois biomas rio-grandenses.

Além disso, considerando que os biomas são responsáveis por inúmeros benefícios para a vida, desde a dispersão de sementes, a procriação de espécies, a polinização, entre outros, e que a ação humana tem influenciado de maneira significativa e acelerada, geradas pela falta de cumprimento de leis de preservação ambiental, pela ampliação e eliminação de territórios, pela plantação de espécies exóticas, monoculturas, intervenções florísticas e faunísticas, entre outros fatores, leva a questionamentos sobre o futuro, sobre as possibilidades de preservação desses, como o caso do bioma Pampa, exclusivo do estado do Rio Grande do Sul, e dentro deste, o ecossistema do Banhado do Taim, de importância ecológica, de peculiar beleza, pouco conhecido e necessário para a perpetuação de espécies.

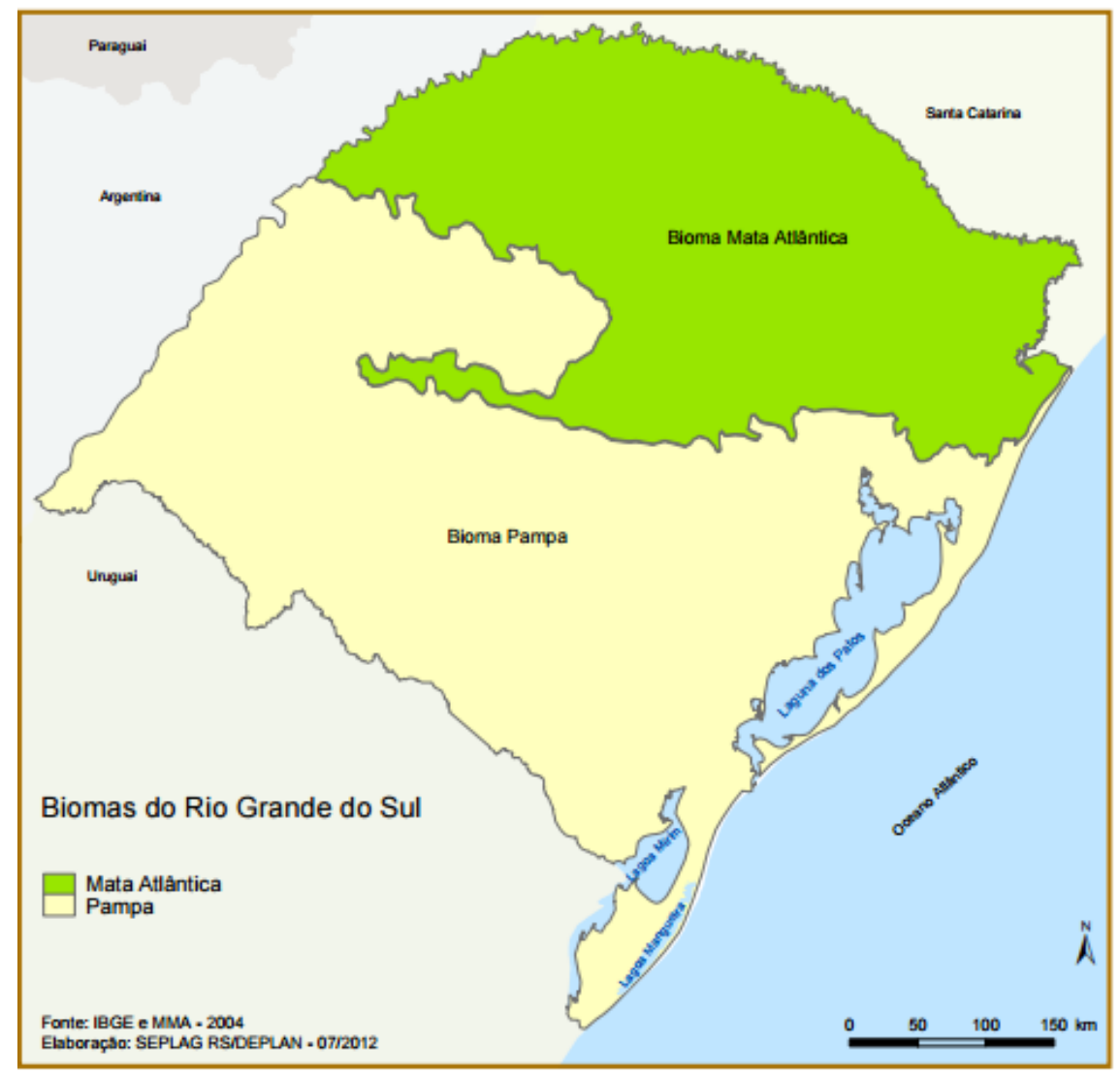

Figura 1 - Mapa dos Biomas do Rio Grande do Sul. Disponível em: Atlas Sócioecnômico do Rio Grande do Sul. Acesso em 11 de março de 2017. 
XVII Simpósio Brasileiro

de Geografia Fisica Aplicada

I Congresso Nacional

de Geografia Física
OS DESAFIOS DA GEOGRAFIA FÍSICA NA FRONTEIRA DO CONHECIMENTO

Instituto de Geociências - Unicamp

Campinas - SP

28 de Junho à 02 de Julho de 2017

\section{Aspectos biogeográficos dos biomas rio-grandenses}

\subsection{Bioma Mata Atlântica}

Segundo o Manual de Adequação Ambiental (2010) a Mata Atlântica é um conjunto de formações florestais diversas, compreendendo campos naturais, restingas, manguezais e outros tipos de vegetação. Considerada por Câmara e Galindo-Leal (2005, p. 27) como um mosaico de biodiversidade, a Mata Atlântica é composta por vários tipos de vegetação, distribuídas ao longo de $27^{\circ}$ de latitude sul, com grande variações de altitude, que estão sob pressão por uma longa história de exploração dos recursos, que eliminou a maioria dos ecossistemas naturais, restando menos de $8 \%$ da extensão original da floresta. Em decorrência disso, houve a perda e a fragmentação de habitats que levaram a extinção de muitas espécies.

Considera-se três formações básicas da Mata Atlântica: Floresta ombrófila densa e aberta, Floresta ombrófila mista e Floresta sazonal e semidecidual, além de numerosas zonas de transição (CÂMARA E GALINDO-LEAL, 2005, p.34).

No Rio Grande do Sul, segundo Câmara e Galindo-Leal (2005, p.34), o bioma Mata Atlântica está representado por vegetações específicas de floresta ombrófila mista, com os dois gêneros de coníferas nativas do Brasil, Araucaria e Podocarpus, e diversos gêneros de lauráceas, tais como as canelas Ocotea e Nectandra, além de representantes de outras famílias. Essa floresta distribuía-se quase continuamente sobre o Planalto Meridional, todavia, atualmente, apresenta-se com vegetação nativa praticamente extinta, contendo presença acanhada de pinheiros-do-paraná (Araucaria angustifolia) e imbuias (Ocotea porosa), árvores símbolos do bioma.

O bioma da Mata Atlântica está presente em toda a porção norte e nordeste do estado (Figura 1), com resquícios de florestas na área central. Estes se apresentam como fragmentos de floresta ombrófila mista, na porção central do Planalto Meridional gaúcho, formando pequenas matas com presença de araucárias, e que estão sendo devastadas pelas atividades humanas, em decorrência da expansão agrícola, urbana e industrial intensa nessa região.

Os remanescentes de Floresta Ombrófila Mista, formam refúgios vegetacionais nas áreas de maior altitude do Estado, no extremo nordeste do mesmo. Essa comunidade vegetal, de acordo com o Manual de Adequação Ambiental (2010) possui particularidades florísticas, fisionômicas e ecológicas, influenciadas diretamente pela altitude das áreas.

Há, também, as chamadas Áreas de Tensão Ecológica, que são os encontros entre os campos de altitude e as florestas ombrófilas mistas, que se caracterizam por serem locais de encontro entre dois ou mais tipos de vegetação. 
As Florestas de Araucária são sub-regiões de transição da Mata Atlântica, caracterizadas pela presença de pequenas extensões de campo aberto, algumas com vegetações baixas. Do ponto de vista biogeográfico, essa é uma larga área de transição entre a Mata Atlântica e a biota temperada do Sul (Leite e Klein, 1990 apud Câmara e Galindo-Leal, 2005, p.48). Este bioma possui extrema importância para a sobrevivência de muitas espécies animais e vegetais, em especial, do papagaio charão (Amazona pretrei), endêmico dos estados do Rio Grande do Sul e Santa Catarina, que se alimenta do pinhão, fruto da araucária, e se utiliza dessa árvore como moradia e também para sua reprodução. Lamentavelmente, essa ave está ameaçada de extinção, principalmente pela captura ilegal e comercialização, como animal de estimação (KILPP, 2014).

De acordo com Leal (2005, p. 4), a extensão original desse bioma tem sido suprimida devido às inúmeras ações antrópicas nessas áreas, como exemplo, o corte arbóreo ilegal e a introdução de espécies exóticas, onde a madeira e as folhas são destinadas à produção de erva-mate, utilizadas na marcenaria, industrializadas para produzir celulose, entre outros usos. Assim, dessas matas, sobram os chamados "remanescentes florestais", que são significativos na porção central e nordeste do Rio Grande do Sul e também em Santa Catarina, Paraná e São Paulo.

Segundo o Ministério do Meio Ambiente (2010, p. 47), as áreas de preservação permanente na Mata Atlântica são de extrema importância ambiental, com funções de proteção de recursos hídricos, estabilidades geomorfológicas, conservação da paisagem, entre outras formas. Porém, essas áreas são muito frágeis e pequenas, pois, hoje, estão distribuídas em forma de fragmentos, e ficam literalmente, encurraladas pelas ações do homem. As Leis ambientais são bem claras no papel, porém, na prática, não são cumpridas pelas indústrias, construções civis e rodoviárias, e, inclusive, por ocupação urbana ilegal de áreas de preservação permanente, fato que ocorre em todo o estado por pressões políticas, econômicas e sociais.

Esses fatos, geram a perda da biodiversidade através da supressão de ecossistemas, populações, variabilidades genéticas, espécies e processos ecológicos e evolutivos que mantêm essa diversidade. Além disso, há um agravante: este bioma possui o maior contigente populacional, então, a relação entre crescimento da população tem levado à destruição da mata, com a expansão urbana, industrialização e migrações, e, ainda, a derrubada de florestas para desenvolvimento agrícola.

Outro bioma importante presente no estado do Rio Grande do Sul é o bioma Pampa, talvez, mais devastado que a Mata Atlântica, pela falta de conhecimento e por suas características ecológicas peculiares. 


\subsection{Bioma Pampa}

O bioma Pampa, no Brasil, está presente no estado do Rio Grande do Sul e também na Argentina e Uruguai. Ele ocupa uma área de $176,5 \mathrm{~km}^{2}$ e é constituído principalmente por campos, onde a vegetação é rasteira, predominantemente gramínea, e por esse motivo, se encontra suprimido, cedendo espaço para a agricultura. (STEFANELLO, 2010).

Segundo as percepções de Marchi (2015, p. 59), a família Poaceae é uma das principais representantes da composição floral nos campos do estado, sendo de $16,4 \%$ da cobertura floral do Rio Grande do Sul, representada por 422 diferentes espécies, das 2.579 existentes no Estado.

Entre algumas das principais espécies de gramíneas encontradas neste bioma, destacamos: O capim-mimoso (Agrostis montevidensis), a barba-de-bode (Aristida megapotamica), a barba-de-bodenativa (Aristida riograndensis) (endêmica do Rio Grande do Sul), e o capim-limão (Elionurus muticius). Como afirma Marchi (2015), essas espécies também são consideradas ornamentais e de uso fitoterápico, a partir de estudos recentes, mas isso nem sempre foi assim, pois como planta rasteira, por muito tempo foi considerado capoeira ou capoeirão, portanto, foi sendo retirado e suprimido como espécie invasora e destituída de valor.

Este bioma ocupa $63 \%$ do território gaúcho, estando presente, predominantemente, na porção sudoeste e sul do estado. De acordo com Moura (2011), o bioma apresenta 35,89\% de cobertura vegetal nativa e 54,17\% de vegetação suprimida. Isso se deve, principalmente, pela expansão das áreas de cultivo de grãos e de introdução de espécies arbóreas exóticas, como o eucalipto e o pinus para a posterior produção de celulose.

É facilmente notável que a vegetação nativa das regiões do Pampa está em processo de extinção, as áreas de produção agropecuária ocupam esses espaços e transformam a paisagem de forma com que haja alterações irreversíveis nos ecossistemas, isso reconhecido por Witter (2016, p. 99) "em diversos ambientes, a agricultura avança sobre as áreas naturais em velocidade incompatível com a capacidade dos pesquisadores em estudar sua fauna e sua flora”. A exemplo disso, Witter (2016, p. 99), refere-se à fauna de polinizadores, em especial das abelhas nativas do Estado, com destaque para as espécies da tribo Meliponini, grandes produtoras de mel, e da família Megachilidae, encontradas facilmente em áreas abertas, mostrando-se tão importantes para a alimentação de outros animais e também dos seres humanos.

O mesmo autor ainda afirma que "o serviço ambiental da polinização prestado pelas abelhas silvestres em campos nativos do bioma ainda é pouco conhecido e valorizado. Esse serviço, para ser gratuito, só pode ser disponibilizado a partir da conservação da biodiversidade" (2016, p. 99). Ou seja, é 
preciso que haja um maior comprometimento nas práticas de gestão de conservação dessas áreas florestais e de campos, visando a proteção dessas espécies polinizadoras, tendo em vista a importância dos serviços prestados por elas.

Na região central do Rio Grande do Sul, caracteriza-se um clima mais seco e com baixos níveis de precipitação anual, além de vegetação rasteira. Essas áreas contam com a presença de gramíneas e arbustos baixos, distantes uns dos outros, árvores de pequeno porte, cactáceas, flores, ervas e extensos campos.

A fauna da região do município de Santa Maria, como exemplo, localizado nesse compartimento, é constituída, principalmente por Ratões-do-banhado (Myocastor coypus), Cevídeos (cevidae) e outras espécies de peixes e répteis. Nota-se presença significativa de médias propriedades, com produção agropecuária, e destaque para a produção de gado, ovelha e criação de cavalos.

É importante destacar a extensa plantação de espécies exóticas, como o pinus (Pinus elliottii) e o eucalipto (Eucalyptos globulus), que são espécies destinadas a reflorestamentos, com características edafoclimáticas de grande adaptabilidade em diferentes condições climáticas, de rápido crescimento e grande absorção de água, localizando-se desde a região central até o compartimento geomorfológico do Escudo Cristalino, ainda evidenciada em diversas regiões do Rio Grande do Sul e também nos estados do sul e sudeste brasileiro.

“...o Bioma Pampa tem sido local para investimentos estrangeiros no plantio de monoculturas de espécies exóticas, com uma ilusória 'solução para os problemas ambientais', por tratar-se de plantio de árvores". (FIGUEIRÓ e SELL, 2010 apud MATEI e FILIPPI, 2013, p. 741).

O plantio de pinus, no Brasil, concentra-se de forma esmagadora na região sul, correspondendo a 79,8\% do total (BARROS, 2011, p.12). Essa monocultura gera economia e comércio exterior para a região, todavia, há muitas preocupações devido a esse intenso "reflorestamento" para a ecologia local. Segundo Figueiró e Sell (2010, p. 6), essas espécies de árvores exóticas consomem muita água presente no solo e entorno, contribuindo para a diminuição do fluxo dos rios e córregos, provocando erosões no solo e a perda de nutrientes, empobrecendo-o para a produção agrícola e substituindo a vegetação nativa.

Nessa área do Rio Grande do Sul, sob o compartimento geomorfológico do "Escudo Cristalino", a vegetação mostra-se um pouco mais densa, onde as árvores possuem maior porte e apresentam-se mais próximas umas das outras, que de acordo com Pillar (2009, p. 292) são os chamados "Mosaicos Campo- 
Floresta", com fisionomias variadas, incluindo resquícios de Floresta Ombrófila Mista, influenciados pelo tipo de solo e altitude da região, que atinge 400 metros em algumas áreas serranas.

A flora é constituída de hortênsias, figueiras e outras árvores frutíferas, contudo, chama a atenção para a quantidade de Vinhedos e Terroirs, que são áreas limitadas para a produção agrícola, principalmente de videiras, além de intensa silvicultura e da plantação de pinus e eucaliptos, denotando a intensa ação humana nesta região.

Por outro lado, de acordo com Carneiro, (2016, p. 32), a região do Escudo Cristalino possui inúmeras espécies de plantas xerófilas, contando com 29 espécies de cactos, sendo a região do estado que mais possui essas espécies. Dessas 29, 26 estão ameaçadas de extinção, principalmente por causa da coleta ilegal, mineração e pela expansão da silvicultura, e 4 dessas espécies são endêmicas do Rio Grande do Sul, onde destacam-se: Cereus hildmannianus; Echinopsis oxygona; Frailea phaeodisca e Gymnocalycium horstii (CARNEIRO, 2015, p. 25). Situação que demanda gestão ambiental e fiscalização de órgãos competentes, pois é um ecossistema de fragilidade ambiental.

Além disso, a região apresenta intenso processo de cultivo de arroz, pecuária e extrativismo, principalmente com plantação de acácias, que são semelhantes aos pinus. A fauna da região compreende espécies de tatus, veados do campo, quero-queros, aves, répteis de pequeno porte, entre outros.

Existe a presença de caraguatás (Bromelia pinguin), espécies endêmicas do Rio Grande do Sul, encontradas facilmente em banhados e matas ciliares. Essas plantas são espinhosas, apresentando folhas longas e duras, com coloração variante. Quando essas plantas ocupam grandes áreas, formam barreiras que servem para esconderijo de jacarés, serpentes, tatus, entre outros animais.

Outra consideração é a importância das palmeiras de butiás (Butia odorata) na região do Escudo Cristalino, que, de acordo com Barbieri (2015), são recursos alimentares de grande valor para a fauna nativa, que retribuem semeando novas plantas no solo através da dispersão das mesmas pelas fezes. Essas populações dos butiazais estão ameaçadas principalmente pela ocupação humana e expansão de plantações, constituindo-se uma preocupação pela falta de regeneração das palmeiras jovens, que se mostram escassas em dias atuais. (BARBIERI, 2015).

A fauna nos butiazais do Pampa é bastante diversa. Existem animais como: O Saracuruçu (Aramides ypacaha), o Bem-te-vi (Pitangus sulphuratus), o Irerê (Dendrocygna viduata), a Corujaburaqueira (Athene cunicularia), o Lagarto-teiú (Salvator Merianae), e o Graxaim-do-campo (Pseudalopex gymnocercus). Além desses, também são encontradas inúmeras espécies de aracnídeos e insetos, como: a Aranha-da-grama (Lycosa erythrognatha), a Aranha-carangueiro (Heteropoda venatoria), 
XVII Simpósio Brasileiro de Geografia Física Aplicada

I Congresso Nacional de Geografia Física
OS DESAFIOS DA GEOGRAFIA FÍSICA NA FRONTEIRA DO CONHECIMENTO

Instituto de Geociências - Unicamp

Campinas - SP

28 de Junho à 02 de Julho de 2017

formigas Sarassará (Camponotus rufipes), e a Paquinha, ou Cachorrinho-da-terra (Neocurtilla hexadactyla). (BARBIERI, 2015).

Em relação à fauna, os grupos zoológicos de maior destaque ocorrem na área municipal de Pelotas, já na região litorânea do estado, e, por ser uma área de banhados, o bioma é caracterizado, principalmente, pela presença de manguezais, restingas e dunas. Nas margens úmidas do litoral, podem ser encontradas variados tipos de espécies de flores e plantas. Rambo (1956, p.22) traz em sua obra exemplos de algumas espécies, como: as Jussieua, as Ciperáceas e as Juncáceas, já nas zonas mais secas, espécies rasteiras, como leguminosas e uma típica planta carnívora das dunas, a Drosera brevifolia.

Todavia, de acordo com Carneiro (2016, p. 33), restam apenas 33\% da cobertura de remanescentes naturais nessa região, onde as principais causas para esse baixo percentual devem-se a expansão urbana, orizicultura e silvicultura.

No entanto, ainda restam áreas importantes desse bioma no Estado, que, por sua vez, são de natureza inigualável, de grande interesse ambiental, possuidora de um ecossistema único, com expressivo número de aves catalogadas e também pela exuberante beleza cênica de sua flora e fauna, que é a Estação Ecológica do Taim.

\subsubsection{Estação Ecológica do Taim}

A Estação foi criada em 21 de julho de 1986, possui uma área de 33.876 hectares e está localizada na Planície Costeira, numa faixa de terra estreita, localizada entre o Oceano Atlântico (a leste) e a Lagoa Mirim (a oeste) A Reserva Ecológica do Taim compreende inúmeros ecossistemas, e, na maioria deles, há presença de banhados, pântanos e praias lagunares, que se mostram abundantes nessa região. (CNUC Cadastro Nacional de Unidades de Conservação, 2012).

É um dos principais e mais diversificados ecossistemas do Brasil (Figura 2). 
XVII Simpósio Brasileiro de Geografia Física Aplicada

I Congresso Nacional de Geografia Física
OS DESAFIOS DA GEOGRAFIA FÍSICA NA FRONTEIRA DO CONHECIMENTO

Instituto de Geociências - Unicamp

Campinas - SP

28 de Junho à 02 de Julho de 2017

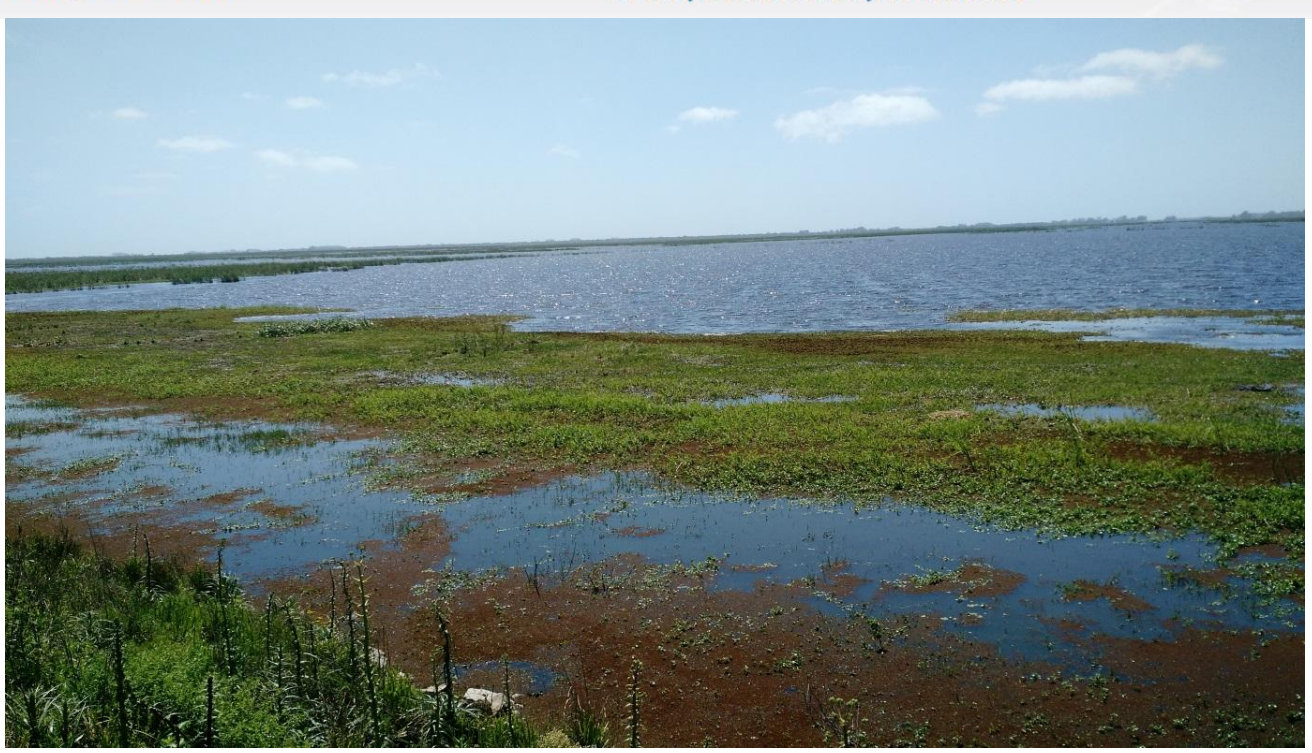

Figura 2 - Ecossistema na Estação Ecológica do Taim/RS. Fonte: Autor, 2016.

De acordo com informações do Cadastro Nacional de Unidades de Conservação - Ministério do Meio Ambiente, 2017, a Estação Ecológica do Taim possui 220 espécies de plantas medicinais catalogadas, em torno de 322 espécies de aves, 28 espécies de mamíferos, 24 de répteis e 18 de anfíbios e conforme o mesmo referencial bibliográfico, segue a lista dos principais animais e seus nomes científicos oficiais encontrados nesta reserva:

- Entre as principais aves, encontram-se: o João-de-barro (Furnarius rufus), o Maguari (popularmente conhecido como João-grande) (Ciconia maguari), o Biguá (Phalacrocorax brasilianus), o Tachã (Chauna torquata), a Caraúna (Plegadis chihi), a Garça-moura (Ardea cocoi), a Cabeça-seca (Mycteria americana), o Socozinho(Butorides striatus), o Ximango (Milvago chimango) e o Cisne-de-pescoço-negro (Cygnus melanocoryphus);

- Entre os principais mamíferos, encontram-se: a Capivara (Hydrochoerus hydrochaeris), (Figura 3), o Ratão-do-banhado (Myocastor coypus), o Cachorro-vinagre (Speothos venaticus), a Lontra (Lutra longicaudis), e o Tuco-tuco (Ctenomys haigi); e

- Entre os principais répteis, destacam-se as espécies: O Jacaré-de-papo-amarelo (Caiman latirostris), a Tartaruga-tigre-d'água (Trachemys dorbigni), e o Cágado-pescoço-decobra (Hydromedusa tectifera).

- E, por fim, algumas das principais espécies de anfíbios presentes na Estação Ecológica do Taim:

O Sapinho-de-barriga-vermelha (Melanophryniscus dorsalis), o Sapo-de-areia (Rhinella arenarum), e a Rã-touro (Lithobates catesbeianus). 


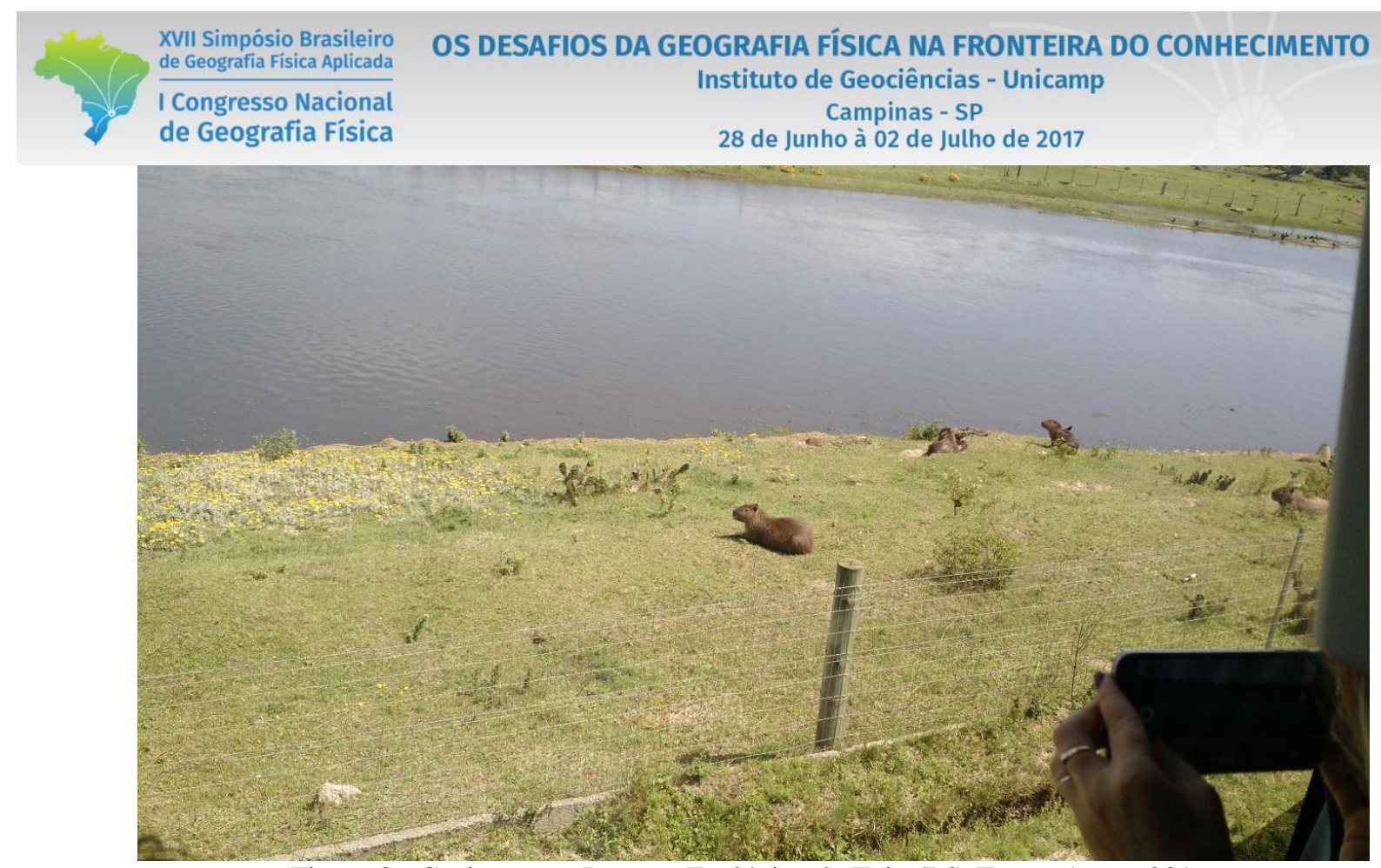

Figura 3 - Capivaras na Reserva Ecológica do Taim/RS. Fonte: Autor, 2016.

Além disso, a Estação Ecológica do Taim, também é um importante berçário das aves migratórias, que viajam milhares de quilômetros de norte ao sul (Ártico e Antártida). A estação raramente sofre com a seca, pois as chuvas nessa região são abundantes e bem distribuídas, fazendo com que os ecossistemas funcionem com regularidade de precipitação, umidade e outros fatores climáticos.

Dentre a flora, o Taim possui uma diversidade abundante de plantas, como: a corticeira-dobanhado (Erythrina cristagalli), as Figueiras (Ficus carica), as Quaresmeiras (Tibouchina grânulos), as Lélias (Cattleya purpurata), as Bromélias (Nidularium), algumas espécies de Juncos (Juncus effusus), o Ipê-amarelo (Handroanthus albus) e também podem ser encontradas algumas espécies de cactáceas, como: O Cacto-macarrão (Rhipsalis bacífera) e o Cacto-rabo-de-rato (Lepismium cruciforme).

A necessidade de preservação da estação ecológica é indiscutível, porém as ameaças à biodiversidade presente nesse ecossistema são facilmente notáveis. Essas, a partir da construção de moradias e estradas, queimadas, presença de resíduos sólidos (lixo), vestígios de motocicletas e outros veículos, expansão agrícola, pescas ilegais, entre outros problemas sociais e ambientais. Além disso, ao percorrer a rodovia BR 471, que atravessa o banhado do Taim, observa-se um número expressivo de atropelamentos de animais, principalmente de capivaras. Esta rodovia, por Lei, exige que os motoristas não ultrapassem os $50 \mathrm{~km} / \mathrm{h}$, todavia, essa não é cumprida.

Portanto, é notável a falta de planejamento e compromisso ambiental na Reserva, visto que não existem corredores ecológicos, equipamentos controladores de velocidade na rodovia, entre outras formas de proteção da reserva que deveriam ocorrer. De modo que, a Estação Ecológica do Taim é, 


\section{OS DESAFIOS DA GEOGRAFIA FÍSICA NA FRONTEIRA DO CONHECIMENTO \\ Instituto de Geociências - Unicamp \\ Campinas - SP \\ 28 de Junho à 02 de Julho de 2017}

lamentavelmente, desvalorizada pela sociedade e seus dirigentes políticos, que não dão a devida importância para esse ecossistema, também não há uma fiscalização regular dos habitats de centenas de espécies, contando com número reduzido de funcionários e poucos recursos.

\section{Considerações Finais}

O Estado do Rio Grande do Sul dispõe de uma biodiversidade impressionante, sendo o habitat de milhares de espécies de plantas, animais e vegetais, que lutam pela sobrevivência, em oposição às ações antrópicas, e, que ao longo do tempo, através da exploração agrícola e da pecuária intensiva e extensiva, mais presente no Bioma Pampa, foram sofrendo os impactos da ocupação humana. Ainda, a expansão urbana, a industrialização que gera poluição, a plantação de espécies exóticas, a falta de planejamento adequado do solo, o uso intensivo de agrotóxicos, os desmatamentos, as queimadas, entre outras formas que alteram consideravelmente a paisagem, contribuindo para a perda da biodiversidade.

Portanto, preservar os biomas do Rio Grande do Sul é uma necessidade para manter a vida silvestre e evitar a destruição ou supressão de áreas tão importantes para a conservação do patrimônio ambiental e ecológico do estado, consequentemente, para as espécies adaptadas a esse espaço geográfico tão peculiar. Isso exige a implementação de órgãos fiscalizadores que façam cumprir as leis ambientais de forma mais efetiva, para que não caia no esquecimento e não sejam banalizadas por projetos políticos que desmantelam órgãos inteiros com o propósito de "corte de gastos".

É preciso levar informações a sociedade, principalmente dos resultados das pesquisas científicas, a fim de ganhar espaço na mídia, e sensibilizar a população sobre a importância da conservação da fauna e da flora para o equilíbrio dos ecossistemas e de toda a biodiversidade, consequentemente, contribuindo para a qualidade de vida dos seres humanos.

\section{Considerações Finais}

BARBIERI, Rosa Lía. (Ed.técnica). Vida no butiazal. Embrapa, Brasília, DF: 2015.

BARROS, Carlos Juliano; CAMPOS, André. Deserto Verde - Os impactos do cultivo de eucaliptos e pinus no Brasil, ONG Repórter Brasil, 2011. Disponível em: http://reporterbrasil.org.br/wp-content/uploads/2015/02/8. caderno_deserto_verde.pdf. Acesso em: 17 de novembro de 2016.

CARNEIRO, Andréia. Cactos do Rio Grande do Sul. Porto Alegre, RS. Fundação Zoobotânica do Rio Grande do Sul, Projeto RS Biodiversidade, 2016. Disponível em: http://www.fzb.rs.gov.br/upload/20160503165856cactos_do_rio_grande_do_sul.pdf. Acesso em: 08 de fevereiro de 2017.

DIAS, Gabriela. Aula Pampa, PasseiDireto, UFLA, Lavras/Minas Gerais, 2016. Disponível em: https://www.passeidireto.com/arquivo/23306375/aula-pampa. Acesso em: 11 de novembro de 2016. 
ESEC Taim, Estação Ecológica do Taim. Wikipédia. Disponível em: https://pt.wikipedia.org/wiki/Esta\%C3\%A7\%C3\%A3o_Ecol\%C3\%B3gica_do_Taim. Acesso em: 17 de novembro de 2016.

FIGUEIRÓ, Adriano. O Bioma Pampa e o Modelo de Desenvolvimento Em Implantação No Alto Camaquã, Universidade de Coimbra, Coimbra/Portugal, 2010. Disponível em: http://www.uc.pt/fluc/cegot/VISLAGF/actas/tema3/adriano_jaciele. Acesso em: 11 de novembro de 2016.

GALINDO-LEAL, Carlos, CÂMARA, Ibsen de Gusmão (Edit.). Mata Atlântica: biodiversidade, ameaças e perspectivas. São Paulo, SP: Fundação SOS Mata Atlântica - Belo Horizonte: Conservação internacional, 2005.

KILPP, Jonas Claudiomar et al. Instalações de caixas-ninho como estratégia para conservação do papagaiocharão (Amazona pretrei). Ornithologia, Revista Científica do CEMAVE, v. 6, n.2, Ministério do Meio Ambiente, 2014. Disponível em: http://cemave.net/publicacoes/index.php/ornithologia/article/view/180/137. Acesso em: 12 de fevereiro de 2017.

MATEI, Ana. O Bioma Pampa e o Desenvolvimento Regional no Rio Grande do Sul, Pontifícia Universidade Católica do Rio Grande do Sul, Porto Alegre/Rio Grande do Sul, n/d (no data = sem data). Disponível_em: http://www.pucrs.br/eventos/eeg/download/Mesa8/O_Bioma_Pampa_e_o_Desenvolvimento_Regional_no_RS.pdf. Acesso em: 11 de novembro de 2016.

MATEI, Ana. O Bioma Pampa e o Desenvolvimento Socioeconômico em Santa Vitória do Palmar, Fundação de Economia e Estatística Siegfried Emanuel Heuser, Porto Alegre/RS, 2013. Disponível em: http://revistas.fee.tche.br/index.php/ensaios/article/viewFile/3019/3208>. Acesso em: 11 de novembro de 2016.

MARCHI, Marene Machado, BARBIERI, Rosa Lía. Cores e formas no bioma Pampa: Gramíneas ornamentais nativas. Brasília, DF: Embrapa 2015.

MINISTÉRIO DO MEIO AMBIENTE. Unidade de Conservação: Estação Ecológica do Taim. Secretaria de Biodiversidade e Florestas, Departamento de Unidades de Conservação, Brasília, DF, 2017. Disponível em: $\mathrm{http} / / /$ sistemas.mma.gov.br/cnuc/index.php?ido=relatorioparametrizado.exibeRelatorio\&relatorioPadrao=true\&idUc =70. Acesso em: 09 de janeiro de 2017.

MINISTÉRIO DO MEIO AMBIENTE. Mata Atlântica: Manual de Adequação Ambiental. Secretaria de Biodiversidade e Florestas, Departamento de Unidades de Conservação, Brasília, DF, 2010. Disponível em: http://www.mma.gov.br/estruturas/202/_arquivos/adequao_ambiental_publicao_web_202.pdf. Acesso em: 09 de janeiro de 2017.

PILlAR, Valério. Campos Sulinos - Conservação e uso sustentável da biodiversidade. Ministério do Meio Ambiente, Secretaria de Biodiversidade e Florestas, Departamento de Conservação da Biodiversidade, Brasília, DF, 2009.

RAMBO, Balduíno. A fisionomia do Rio Grande do Sul. Porto Alegre, RS: Livraria Selbach, 1956.

ROMARIZ, Dora de Amarante. Biogeografia: temas e conceitos. São Paulo: Scortecci, 2008.

RIO GRANDE DO SUL. Fundação Zoobotânica do Rio Grande do Sul. Natureza em revista. RS Biodiversidade. Março, 2016.

RS BIODIVERSIDADE, A fauna e a flora do Rio Grande em Boas Mãos. Governo do Estado do Rio Grande do Sul. Disponível em: http://www.biodiversidade.rs.gov.br/arquivos/1161787177FOLDER.pdf. Acesso em: 16 de novembro de 2016.

STEFANELlO, Regina. Bioma Pampa gaúcho e espécies endêmicas, UFSM, Santa Maria/Rio Grande do Sul, 2010. Disponível em: http://biogeografia-ufsm.blogspot.com.br/2010/06/bioma-pampa-gaucho-e-especiesendemicas.html. Acesso em: 16 de novembro de 2016. 